\title{
Artificial intelligence in multimedia computing
}

Published online: 2 January 2020

C Springer Science+Business Media, LLC, part of Springer Nature 2020

Multimedia Tools and Applications gratefully acknowledges the editorial work of the scholars listed below on the special issue entitled "Artificial Intelligence in Multimedia Computing".

Of 79 papers submitted to this issue, 19 were eventually accepted after a stringent peerreview process.

\section{Corresponding Guest Editor}

\section{Dr. Jing Tian}

National University of Singapore, Singapore

Email: tianjing@nus.edu.sg

\section{Guest Editors}

\section{Prof. Li Chen}

Wuhan University of Science and Technology, Wuhan, China

Email: chenli@wust.edu.cn

\section{Dr. Xin Xu}

Wuhan University of Science and Technology, China

Email: xuxin0336@gmail.com

Publisher's note Springer Nature remains neutral with regard to jurisdictional claims in published maps and institutional affiliations. 